\title{
Erken Müdahale Kapsamında Taranan 0-72 Aylık Çocuklarda Gelişimsel Gecikmelerin Dağılımı
}

\author{
Hülya TERCAN* \\ Pinar BAYHAN ${ }^{* *}$
}

\begin{abstract}
$\ddot{O} z$
$\mathrm{Bu}$ araştırmanın amacı, erken müdahale kapsamında taranan 0-72 aylık Türk çocuklarının gelişimsel olarak şüpheli ya da gecikmeli oldukları gelişim alanlarının neler olduğunu belirlemektir. Bu amaç doğrultusunda Ankara ilinde belirlenen bir çocuk hastanesinde gelişimsel olarak değerlendirilen ve en az bir alanda gelişimsel desteğe ihtiyacı olan 789 çocuk araştırmaya dâhil edilmiştir. Veri toplama aracı olarak Genel Bilgiler Formu ve Denver II Gelişim Tarama Testi kullanılmışıı. Planlanan bu araştırmanın sonucunda, gelişimsel değerlendirme yapılması için yönlendirilen 0-72 aylık çocuklardan erkek çocukların kız çocuklardan daha fazla olduğu görülmüştür. Bunun yanı sıra yapılan gelişim testi sonucunda en az bir alanda anormal veya şüpheli gelişim gösteren grupta da erkek çocukların oranı kız çocuklardan daha fazla olarak bulunmuştur. Ayrıca değerlendirme için yönlendirilen gruplarda anormal veya şüpheli gelişim gösteren çocukların en fazla tüm gelişim alanlarında desteğe ihtiyacı olduğu belirlenmiştir. Bunu gelişimsel olarak en çok sorun yaşanılan alanlar dil ve konuşma alanı ile motor gelişim alanı izlemektedir. Sonuçta yapılan tarama çalışmasının 0-72 aylık çocukların gelişimsel alanları ile ilgili önemli bilgiler verdiği açıktır ayrıca bu tarama çalışması, uzmanlara ve ailelere yaş gruplarına göre bir gelişimsel profil sunmaktadır.
\end{abstract}

Anahtar kelimeler: Gelişimsel değerlendirme, erken müdahale, gelişimsel gecikme

\section{Developmental Evaluation in 0-72 Months Distribution of Developmental Delays}

\begin{abstract}
The aim of this study is to present the general information about the development areas where the Turkish children are 0-72 months old, whose developmental suspicion or delay is scanned in early intervention. For this purpose, 789 children who were evaluated developmentally in a pediatric hospital in Ankara and who needed developmental support in at least one area were included in the study. General information form and Denver II Development Screening Test were used as data collection tools. As a result of this study, it was observed that boys who are 0-72 months old were more than girls. The rate of male children was found to be higher in girls with abnormal or suspicious development in at least one area. In addition, it was determined that children who showed abnormal or suspicious development in the groups directed for evaluation need support in all areas of development. The areas with the most developmental problems are followed by the area of language and speech and motor development. It is clear that the screening study provided gives important information about the developmental areas of 0-72 month-old children, and this study provides experts and families with a developmental profile according to age groups.
\end{abstract}

Key words: Developmental evaluation, early intervention, developmental delay

Received/Geliş: 17.01 .2020

Accepted/Kabul: 24.05.2020

* Bu çalışma, Hacettepe Üniversitesi İhsan Doğramacı Çocuk Hastanesi'ne bağlı çalışan Çocuk Gelişimi Değerlendirme ve Erken Müdahale Ünitesine başvuran hastaların bireysel izinleri ve yasal onamları alınarak gerçekleştirilmiştir.

\footnotetext{
* Öğr.Gör., Hacettepe Üniversitesi Sağlık Bilimleri Fakültesi, Çocuk Gelişimi Bölümü, hulya.tercan@hacettepe.edu.tr, (D/ 0000-0001-7969-6095

** Prof. Dr., Hacettepe Üniversitesi Sağlık Bilimleri Fakültesi, Çocuk Gelişimi Bölümü, pinars@hacettepe.edu.tr, /0000-0002-5466-0376

(Makale türü: Araştırma makalesi)
} 


\section{Giriş}

Dünyada son 20 yılda çocuk gelişimi ve sağlığı ile ilgili önemli çalışmalar yapılmaya başlanmıştır. Bu çalışmalar, özellikle 0-6 yaş döneminde çocukların genel sağlık durumlarının son yıllarda daha iyiye gittiğini gösterse de uluslararası bazı sağlık ölçütleri yine de birçok çocuğun hala gelişimsel olarak savunmasız ve risk altında olduklarını göstermektedir (Dall'Alba et al. 2014). Ülkemiz için bugün, yoksulluk, göç gibi birçok çevresel risk ya da yoksunlukla doğan çocuklara yöneltilecek olumlu müdahaleler planlamak, riskleri hafifletmek ve erken müdahale sağlamanın yollarını araştırmaya devam etmek oldukça önemlidir (Akman, 2018).

Gelişimsel sorunların doğası incelendiğinde, bu sorunların bir dizi fiziksel ya da doğuştan gelen nedenlerden kaynaklanabildiği görülmektedir. Bu nedenler bireyde zihinsel ve / veya fiziksel bir bozukluğa neden olabileceği gibi, dil ve konuşmanın gelişimini, sosyal gelişimi ve bilişsel süreçleri de etkileyebilmektedir (Hannigan, Pingault, Krapohl, McAdams, Rijsdijk \& Eley, 2018). Gelişimsel bozukluklar terimi ise, literatürde neredeyse sayısız koşulu ifade etmek için kullanılmaktadır (Courchesne \& Pramparo, 2018). Ancak en yaygın olarak kullanıldığ durumlar otizm, serebral palsi, davranış bozuklukları ve Down sendromu gibi bozukluklardır. Daha az yaygın ya da şu günlerdeki kullanımı ile "nadir görülen gelişimsel sorunlar”a ise Angelman ya da Rett sendromları örnek olarak verilebilir. (American Psychiatric Association, 2013). Yine de dünyada çocuklarda görülen gelişimsel bozuklukların yaygınlığı konusunda sınırlı bir fikir birliği vardır. Bununla birlikte, çeşitli çalışmalarda yaygınlığın \%4 ile \%6 arasında değiştiği tahmin edilmektedir (Tekola, Girma, Kinfe, Abdurahman, Tesfaye, Yenus \& Servili, 2020).

Gelişimsel gecikmelerin ya da bozuklukların neler olduğuna yönelik rehberlik edecek birçok uluslararası standart bulunmaktadır. Ancak bugüne kadar gecikmelerden etkilenen gelişimsel alanların, bazı değişkinlerle nasıl değiştiği daha az incelenen bir konu olmuştur. Özellikle bebeklik ve erken çocukluk döneminde görülen gelişimsel sorunların yaygınlığına ilişkin çoğu ulusal ve uluslararası tahmin, çocuğun gelişimi ile ilgili doğrudan değerlendirmelerden ziyade, ebeveynlerin cevapladığı sorulara dayanmaktadır. Oysaki gelişimsel gecikmelerin ve nedenlerinin ortaya konması için en önemli basamaklardan biri gelişimsel değerlendirme basamağıdır. Gelişim konusunda uzman bir kişi ya da ekip tarafından planlanan iyi bir gelişimsel değerlendirme, aynı zamanda gelişimsel destek programlarını ve erken müdahaleyi de içermelidir. Erken müdahale çalışmaları 0-72 ay aralığındaki çocuklar için gözetilmesi gereken gelişimsel özellikleri ve mevcut durumu geliştirmeye uygun yaklaşımları içermektedir (Zwaigenbaum et al. 2015). Daha spesifik olarak, bazı erken müdahale programları, bebekleri doğumdan 3 yaşa kadar desteklemeyi hedeflerken bazı müdahalelerde yaş 6 yıla kadar uzatılmıştır. Ama genel olarak müdahalenin başlangıç yaşının, gelişimsel sorunun türüne bağlı olarak değiştiği bilinmektedir. Bu çalışma kapsamında, taranan çocukların müracaat ve 
değerlendirme basamağındaki bilgileri yer almakta ve etkin bir müdahale için, üyeleri mevcut kaynaklara bağlı olarak değişebilen multidisipliner bir ekip yaklaşımı savunulmaktadır. (Swaminath, Hefner, Jenkins, Suarez, Meyerrose \& Huerta, 2018).

Erken desteğin ve müdahalenin sağlanması ile ilgili yapılan çalışmalar incelendiğinde ise, gelişimsel gecikmesi ya da herhangi bir özel gereksinimi olan çocuğun, bazı hizmetlerden faydalanma oranının oldukça sınırlı olduğunu görülmektedir (Sheridan, McLaughlin, Winter, Fox, Zeanah \& Nelson, 2018). Mevcut bilgiler, bu çocukların erken müdahale hizmetlerine de katılım oranlarının bu duruma paralel şekilde düşük olduğunu göstermektedir (Rosenberg et al. 2008). Çocukların hizmetlere katılımı ile ilişkili olan faktörler arasında ırk, cinsiyet, yoksulluk ve sağlık sigortasının kullanılabilirliği gibi unsurlar gösterilmektedir ki bu durum ülkemiz için de oldukça benzer bir şekilde ilerlemektedir. Dolayısıyla bu çalışma, taramaya katılan çocukların sosyo-demografik özelliklerinin gelişimsel durumları ile nasıl bir ilişki içerisinde olduğunu, riskli alanların yoğunluğunu belirlemek açısından önemli görülmektedir. Ayrıca, bu çalışma ile kliniğe gelen her çocuk ve ailesi için son yıllarda yapılan uygulamalar takip edilerek sadece gelişimsel tarama değil ihtiyaca göre destek programların hedefi ile ileriye yönelik çocuk gelişimi alanının işlevleri de değerlendirmeye çalışılmıştır (Bricker, Felimban, Lin, Stegenga \& Storie, 2020).

Tüm bunlar göz önünde bulundurulduğunda planlanan bu araştırmanın amacı, gelişimsel tarama sırasında normal gelişim göstermeyen ya da nadir görülen gelişimsel sorunları olan çocuklar ve sık görülen bozukluklara kadar erken müdahale birimine diğer polikliniklerce yönlendirilen çocukların gelişimsel profillerini belirlenmeye çalışmaktır. Çıkarılan gelişimsel profillerle cinsiyet-yaş özellikleri de dikkate alınarak gelişimsel geriliklerin ya da gecikmelerin alanları araştırılmaktadır. Ayrıca bu çalışmanın bulgularının, tüm hastanelerde bulunan çocuk gelişimi servislerinin hizmet sunumu için kanıt temeline katkı sunacağı ve birçok çocuk gelişimcinin erken müdahalede bulunmak için bulundukları önemli rolü destekleyeceği ön görülmektedir.

\section{Yöntem}

Bu bölümde araştırmanın modeli, çalışma grubu, veri toplama araçları, araştırma süreci ve verilerin çözümlenmesinde kullanılan istatistiksel tekniklere yer verilmiştir.

\section{Araştırma Modeli}

Yapılan bu araştırmada nicel araştırma tekniklerinden betimsel tarama tekniği kullanılmıştır. Tarama modeli, geçmişte ya da halen var olan bir durumu ortaya çıkarmayı amaçlayan bir çalışma olarak tanımlandığ gibi; bir durum ya da olaya ilişkin katılımcıların görüşlerinin veya ilgi, yetenek, tutum vb. özelliklerinin belirlendiği çalışmalar olarak da tanımlamaktadır (Karasar, 2010; Büyüköztürk ve diğerleri 2009). Dolayısıyla bu çalışma halen var olan bir durumu var olduğu şekliyle betimlemeyi amaçladığından araştırmaya uygun bir 
model olduğu görülmektedir. Bu araştırmada erken müdahale kapsamında taranan 0-72 aylık Türk çocuklarının gelişimsel olarak şüpheli ya da gecikmeli oldukları gelişim alanlarının neler olduğu ve bu alanlardaki yoğunlukların yaş gruplarına göre dağılımlarını belirlemek amaçlanmıştır.

\section{Çalışma Grubu}

Çalışma grubunun belirlenmesinde; çocukların yaş aralıklarının 0-72 ay aralığında olması sınırlılığ1 göz önünde bulundurulmuştur. $\mathrm{Bu}$ sınırlılık doğrultusunda araştırmanın çalışma grubunu 2016-2017 yılları arasındaki 1 yıllık süreçte Çocuk Gelişimi Değerlendirme ve Erken Müdahale Ünitesine yönlendirilen ve Denver II Gelişim Tarama Testi’ne göre anormal ya da şüpheli gelişim gösteren 789 çocuk oluşturmaktadır.

Çalışma grubunu oluşturan çocuklar 0-72 ay aralığındadır. Örneklemi oluşturan çocuk grubunun cinsiyete göre dağılımları incelendiğinde \%43'ünün (447) erkek çocuklardan; \%57'sinin (590) kız çocuklardan oluştuğu görülmektedir. Cinsiyete göre yaş aralıklarının dağılımı Grafik 1'de gösterilmektedir.

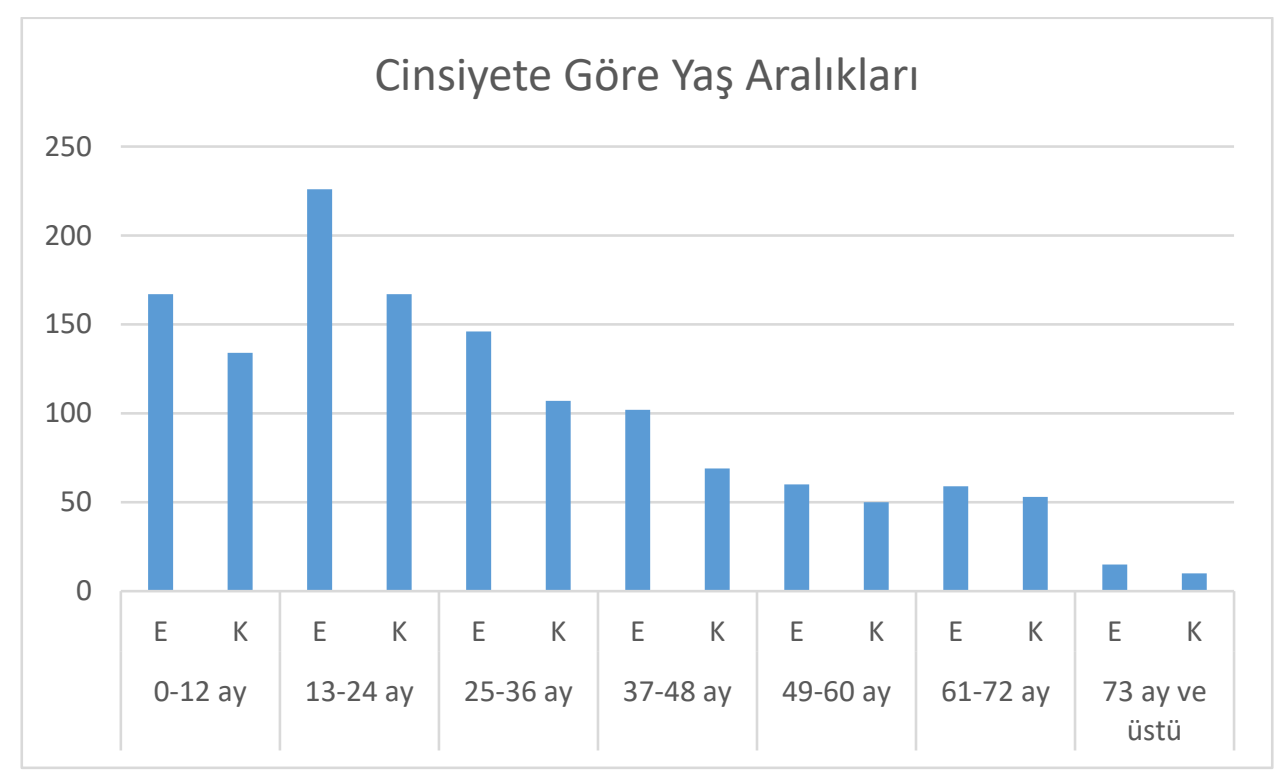

\section{Grafik .1 Çalışma Grubunu Oluşturan Çocukların Cinsiyetlerine Göre Yaş Dağılımları Veri Toplama Araçları}

$\mathrm{Bu}$ araştırmada veriler, çocuk hakkında demografik bilgileri toplamak için oluşturulan Genel Bilgi Formu ve çocukların genel gelişimsel durumlarını belirlemek için de Denver II Gelişim Tarama Envanteri kullanılarak elde edilmiştir.

Genel Bilgi Formu: Bu form, çocuğun cinsiyeti, yaşı, hangi birimden yönlendirildiği, herhangi bir tanısı olup olmadığına ilişkin sorulardan oluşmaktadır.

Denver II Gelişim Tarama Envanteri: Anlar ve Yalaz tarafindan Türk çocuklarına uyarlanıp, geçerliliği ve güvenilirliği yapılan DGTT 0-6 yaş çocuklarda çocuğun yaşına uygun becerileri değerlendiren, gelişimsel sorunları saptamada klinik görüşmeye yardımcı bir gelişim 
envanteridir. Test kişisel-sosyal alan, ince motor, kaba motor ve dil alanında toplam 116 maddeden oluşmaktadır. Ayrıca çocuğun test esnasındaki durumunu değerlendirmeye yarayan 5 ilave soru içermektedir. DGTT II, çocuklarda tarama amacıyla 6 yaşına kadar birden fazla olmak üzere de kullanılmaktadır. Testin uygulanmasına çocuğun kronolojik yaşına uygun noktadan başlanmakta ve maddeler "geçer", "kalır", "olanak dışı" ve "reddetme" biçiminde puanlanmaktadır. Alınan puanlara göre, "normal", "anormal”, "şüpheli” ve "test edilemez" şeklinde yorumlanmaktadır (Anlar, Yalaz 1996). DGTT II' nin geçerlik ve güvenirlik çalışması Yalaz, Anlar ve Bayoğlu tarafından yapılmış olup güvenirlik çalışmalarında değişik yaş gruplarından 10 çocuk aynı anda birden fazla testör tarafından test edildiğinde ve aynı çocukların en fazla 5 gün aralıkla yapılan test sonuçları karşılaştırıldığında testörler arası uyumluluk \%90, test-test uyumluluğu ise \% 86'nın altına düşmemiştir.

\section{Veri Toplama Süreci}

Veri toplama sürecinde Ankara İlinde belirlenen Çocuk Hastanesinde Çocuk Gelişimi Değerlendirme ve Erken Müdahale Ünitesi’ne gelişimsel değerlendirme için yönlendirilen çocukların ve ailelerin çalışma hakkında bilgilendirilmesi ile başlamaktadır. Bu aşamada çocuk ve aileden bilgilendirilmiş onay formları üzerinden çalışmaya gönüllü olarak katılım gösterdiklerine dair bilgiler alınmıştır. Çalışmanın tüm basamakları için Hastane Yönetimi bilgilendirilmiş ve gerekli yasal izinler alınmıştır. Başvuran her bir çocuk ve ailesine öncelikle Demografik Bilgiler Formu sunulmuş sonrasında çocuklara Denver II G.T.T uygulanmış ve sonuçları kaydedilmiştir. Üniteye başvuran 0-72 ay aralığındaki Denver II test sonucu 'anormal' ya da 'şüpheli' olan çocuklar seçilerek bu çocukların hangi birimler tarafindan yönlendirildiği araştırmaya dâhil edilmiştir. Ayrıca test sonucu 'anormal' ve 'şüpheli' çıkan çocukların hangi alanlarda gelişimsel gecikme ya da güçlük yaşadıklarının bilgileri de araştırmada kullanılmak üzere kaydedilmiştir.

\section{Verilerin Analizi}

Elde edilen veriler SPSS 26.00 programına aktarılmış ve istatistiksel olarak değerlendirilmiştir. Analiz aşamasında, sayı ve frekans dağılımı ve ortalama karşılaştırma testleri gibi betimsel analizlere yer verilmiştir.

\section{Bulgular}

Bu bölümde Hacettepe Üniversitesi Çocuk Gelişimi Bölümü Değerlendirme ve Erken Müdahale Ünitesi'nde değerlendirilen çocuklardan anormal gelişim ve şüpheli gelişim gösteren çocukların demografik bilgileri ve güçlük yaşadıkları alanlara yönelik bulgulara yer verilmiştir. 


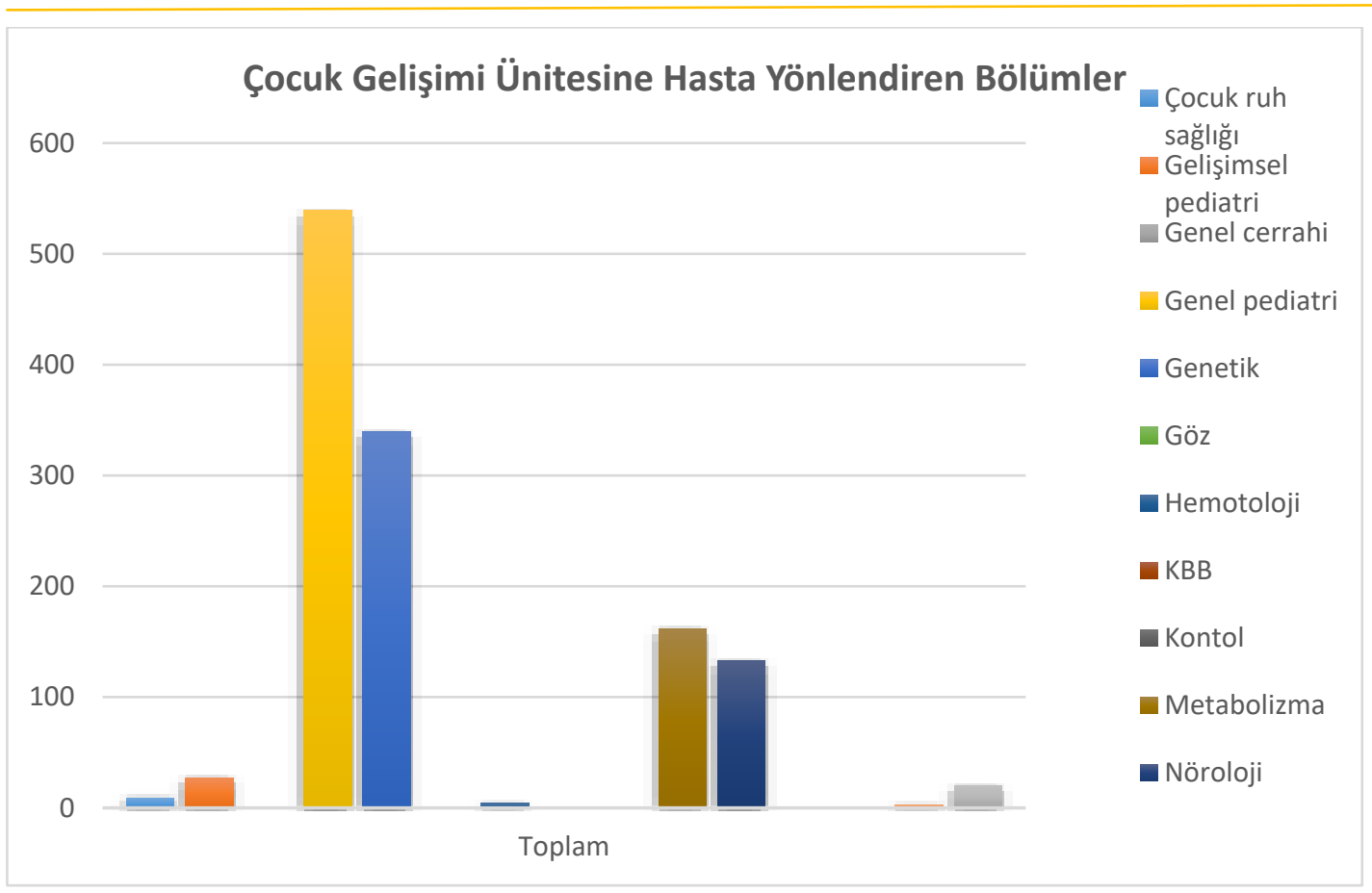

Grafik 2. Çalışma Grubunu Oluşturan Çocukları Yönlendiren Bölümler

Çocuk Gelişimi Değerlendirme ve Erken Müdahale Ünitesine hasta yönlendiren bölümlere bakıldığında, hastaların \%39,3’ü’nün Genel Pediatri polikliniğince yönlendirildiği görülmüştür. Dolayısıyla gelişimsel değerlendirme için yönlendirilen hastalar en fazla bu birimden üniteye giriş yapmışlardır. İkinci sırada Değerlendirme ve Erken Müdahale ünitesince yönlendirilen hastaların \%24,9'u Genetik tarafından yönlendirilmiştir. Hastaların \%12'si Metabolizma, \%10’u Nöroloji tarafindan yönlendirilirken \%6'l1k da izlem yapılan bir hasta grubu vardir.

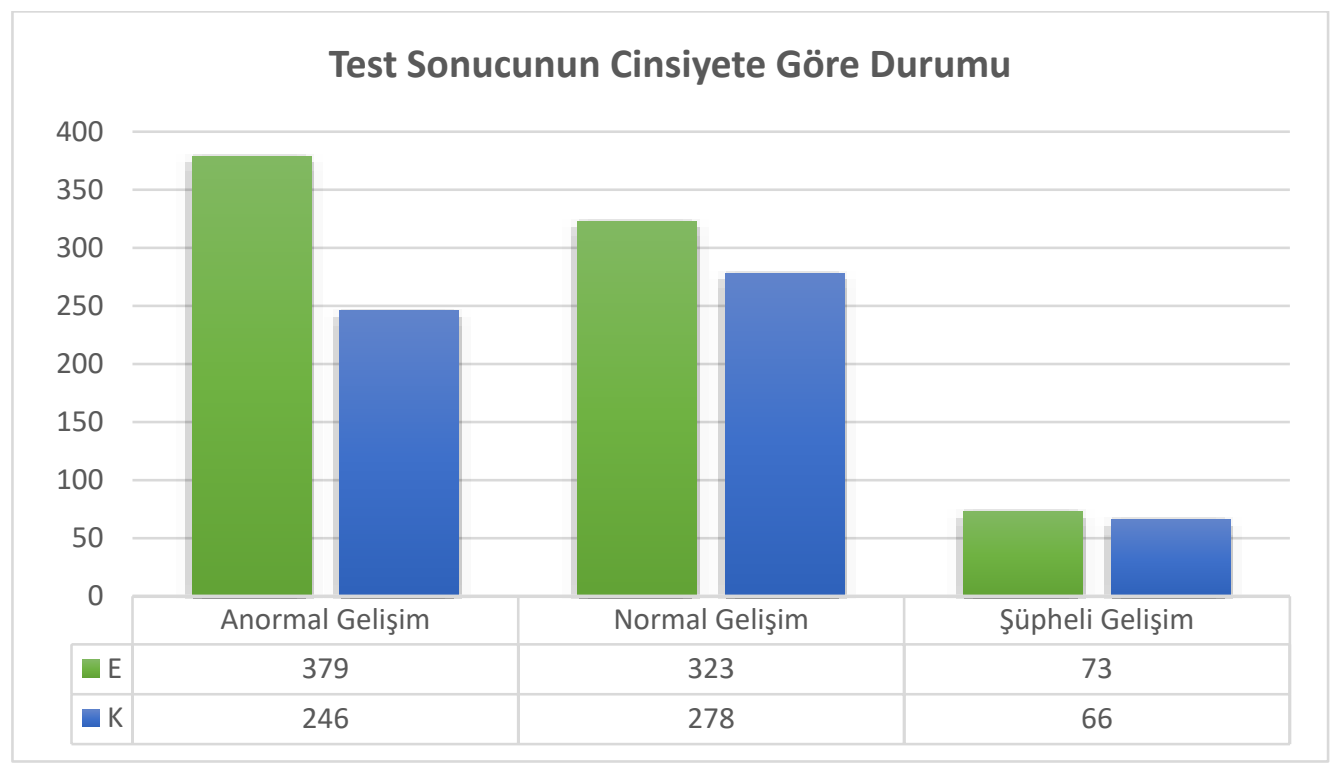

Grafik 3 Çalışma Grubunu Oluşturan Çocukların Denver II G.T.T Sonuçları 
Değerlendirme ve Erken Müdahale Ünitesine yönlendirilen tüm olgular içerisinde 625 çocuğun (45,7) Denver II GTT’ ye göre anormal gelişim gösterdiği, 601 çocuğun (\%44) normal gelişim gösterdiği ve 139 çocuğun ise $(\% 10,3)$ şüpheli gelişim gösterdikleri bulunmuştur.

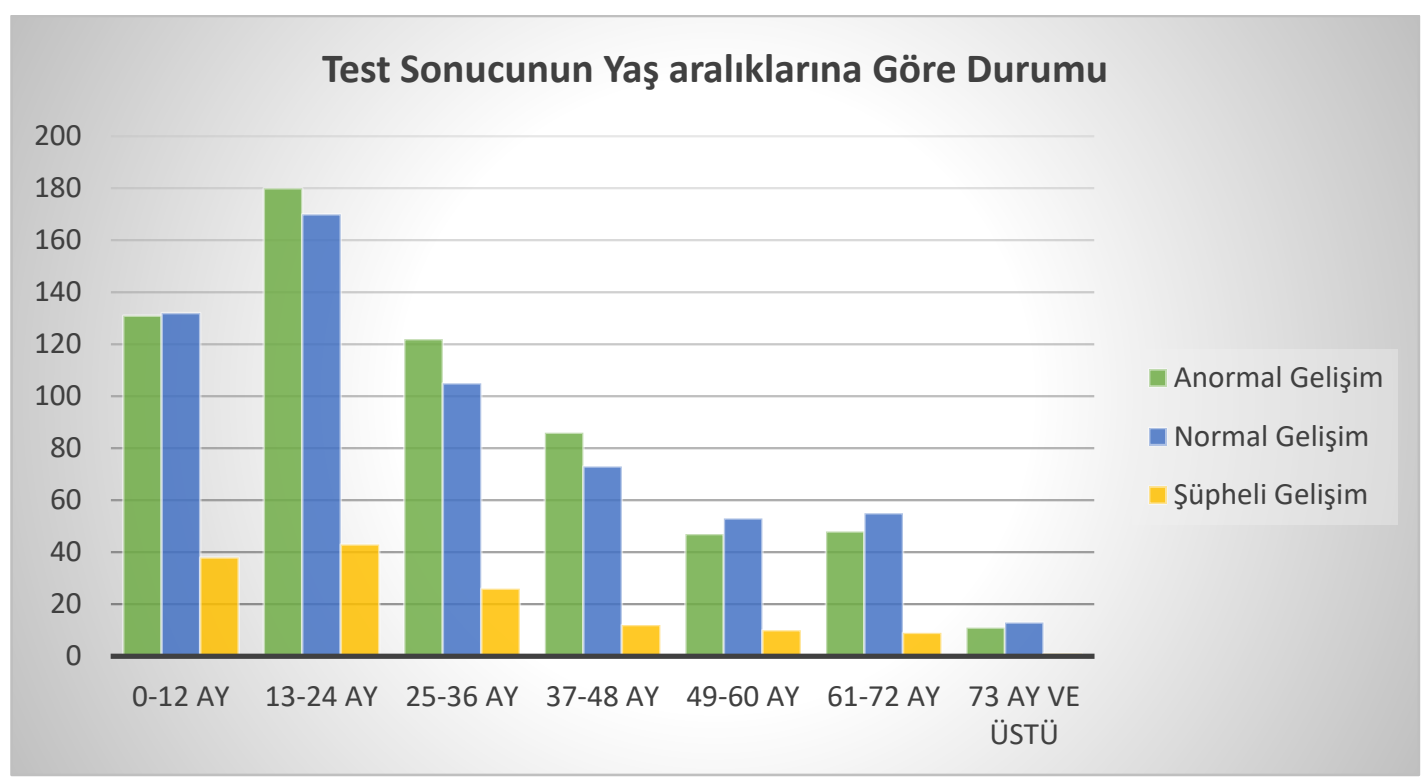

Grafik 4. Çalışma Grubunu Oluşturan Çocukların Denver II GTT Sonuçlarının Yaş Aralıklarının Göre Dağılımı

Çalışmaya dâhil edilen çocukların yaş aralıkları toplam 6 gruba ayrılarak incelenmiştir. Bu gruplar 0-12 ay, 13-24 ay, 25-36 ay, 37-48 ay, 49-60 ay ve 61-72 ay aralığını içerecek şekilde belirlenmiştir. Tüm olgular içerisinde 73 ay ve üzeri başvuran olgular da olmasına rağmen bu çocuklara ait gelişimsel özellikler çalışmaya dâhil edilmemiştir. Çalışma grubunu oluşturan çocukların yaş aralıklarına göre Denver II GTT sonuçları incelendiğinde anormal gelişim ve şüpheli gelişim gösteren çocukların \%29 oranıyla en fazla 13-24 ay aralığındaki yaş grubunda olduğu dikkat çekmektedir. Bunu \%22,2 ile 0-12 ay aralığındaki çocuk grubu izlemektedir. Anormal gelişim gösteren çocukların oranları 25-36 ay aralığında \%18,4, 37-48 ay aralığında $\% 12,4,61-72$ ay aralığında \%8,2 ve 49-60 ay aralığında \%7,6 olarak devam etmektedir.

Genel gelişimsel değerlendirmeleri Denver II GTT ile yapılan ve test sonucu anormal ya da şüpheli çıkan çocukların güçlük yaşadıkları alanlar; dil gelişimi, dil ve ince motor alanda güçlüğün birlikte görülmesi, dil ve kaba motor alanda güçlüğün birlikte görülmesi, dil ve motor alanda (hem ince motor hem kaba motor) güçlügüun birlikte görülmesi, dil ve sosyal alanda güçlüğün birlikte görülmesi, sadece kaba motor alanda görülmesi, sadece kişisel- sosyal alanda görülmesi, motor alanda görülmesi, motor ve sosyal alanda birlikte görülmesi ve tüm gelişim alanlarının tamamında güçlük görülmesi olmak üzere toplam 11 kategoride değerlendirilmiştir. 


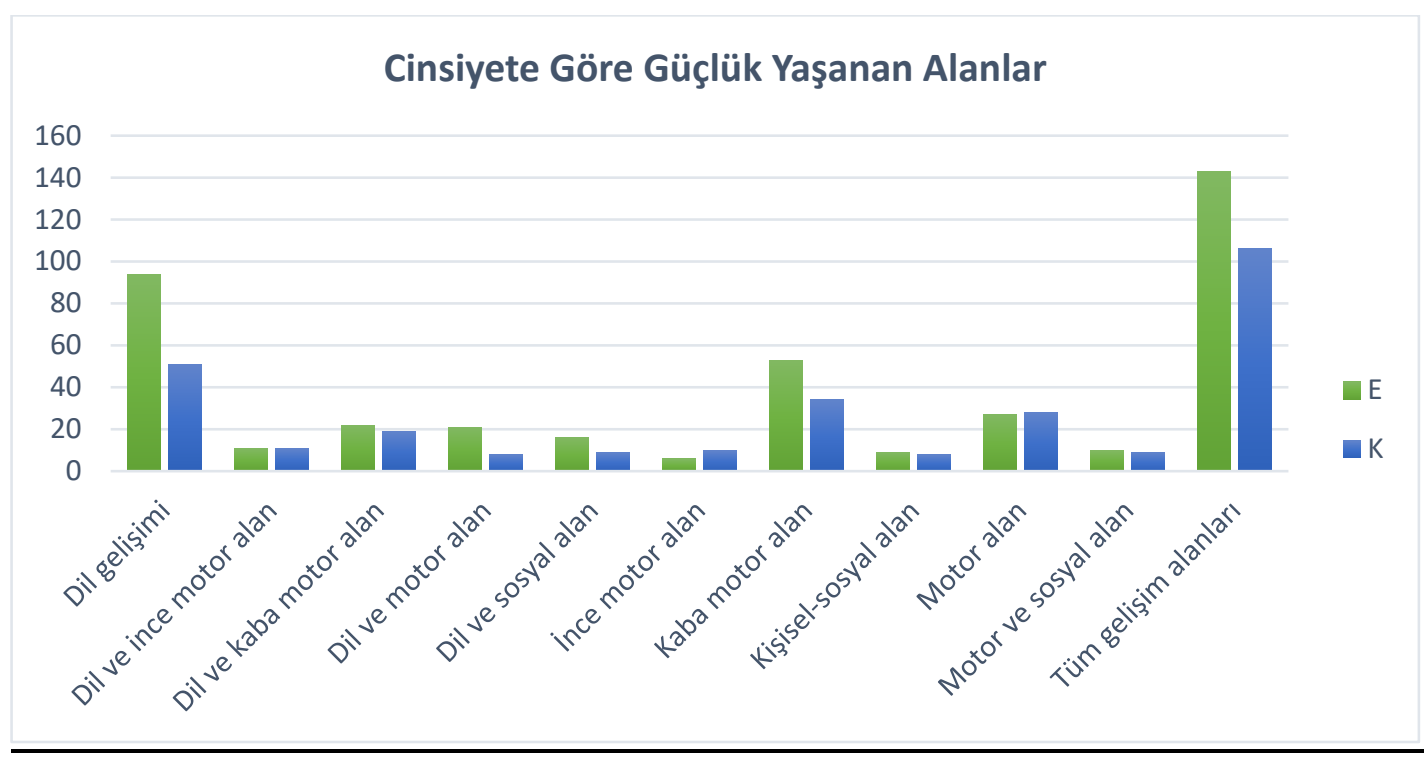

Grafik 5. Çalışma Grubunu Oluşturan Çocukların Cinsiyete Göre Güçlük Yaşadıkları

\section{Alanlar}

Çalışma grubunun cinsiyete göre güçlük yaşadıkları alanları gösteren Grafik 2.3 incelendiğinde, anormal gelişim gösteren çocuklar içerisinde tüm gelişim alanlarının tamamında desteğe ihtiyaç duyan çocuk sayısının en fazla olduğu görülmektedir. Tüm gelişim alanlarında güçlük yaşayan çocukların cinsiyete göre durumuna bakıldığında çoğunluğunun erkek çocuklardan oluştuğu görülmüştür. Güçlük yaşanan alanlarda ikinci sırada dil gelişim alanı gelmektedir. Dil gelişimi ile alakalı yaşanan güçlüklerde cinsiyete göre belirgin bir farkl11ık olduğu görülmüştür. Dilde güçlük yaşayan çocukların büyük çoğunluğunu \%63 ile yine erkek çocuklar oluşturmaktadır. Bu oran kız çocukların oranının (\%37) yaklaşık olarak iki katıdır. En sık güçlük yaşanılan alanlarda üçüncü sırada kaba motor alanla ilgili yaşanan güçlükler gelmektedir. Bunu sirasıyla, motor alan, dil ve kaba motor alan, dil ve motor alan, dil ve sosyal alan, motor ve sosyal alan ve kişisel sosyal alanda yaşanan güçlükler izlemektedir. Bu alanlarda yalnızca ince motor alanda güçlük yaşanan grupta kız çocuklarının daha yüksek bir oranda olduğu, diğer güçlük yaşanan alanların çoğunluğunda erkek çocukların oranlarının daha yüksek olduğu dikkat çekmektedir.

\section{Tartışma}

Yapılan bu araştırmada Çocuk Gelişimi Değerlendirme ve Erken Müdahale Ünitesi'ne yönlendirilen çocukların, gelişimsel taraması yapılarak sıklıkla görülen gelişimsel sorunların bir profili ele alınmıştır. Elde edilen bulguların, tüm hastanelerde bulunan çocuk gelişimi servislerinin hizmet sunumu için kanıt temeline katkı sunacağı ve birçok çocuk geliş̧imcinin erken müdahalede bulunmak için bulundukları önemli rolü destekleyeceği öngörülmektedir.

Konu ile ilgili literatür incelendiğinde, erken müdahale sağlanması gereken gruplar tanımlanırken genellikle üç risk grubundan bahsedilmektedir. Bunlar (1) büyüme ve gelişmeyi 
olumsuz etkileyebilecek yoksun fiziksel ve sosyal çevre nedeniyle dezavantajlı olarak görülen çevresel olarak savunmasız çocuklar, (2) biyolojik olarak risk altında olan çocuklar (örneğin prematüre, fetal alkol sendromu, asfiksi) ve (3) gelişimsel ilerlemeyi olumsuz etkilediği bilinen tıbbi bir tanısı olan çocuklardır (Côté, Orri, Tremblay \& Doyle, 2018). Yaptığımız bu çalışmada literatürde tanımlanan risk grupları ile benzer özellikler gösteren bir örneklem grubu üzerinde tarama yapılmıştır. Ayrıca tarama yapılan çocukların tıbbi ve gelişimsel özellikleri takip edildikleri bölümlere bağlı olarak farklılık göstermektedir. Juneja ve ark tarafindan 2005 yılında yapılan bir çalışmada gelişimsel değerlendirme servislerine yönlendirilen çocukların etiyolojik tanısında doğum komplikasyonlarının ve genetik sorunların eşit derecede yaygın olduğu bildirilmiş̧tir (Juneja ve diğ, 2005; Ensink ve diğ, 2020). Bizim yaptığımız çalışmada da benzer şekilde hastaların \%39,3'ü'nün Genel Pediatri polikliniğince yönlendirildiği, ikinci sırada ise \%24.9 ile genetik tarafından yapılan yönlendirmeler gelmektedir.

Gelişimsel sorunların cinsiyetlere göre farklılaşıp farklılaşmadığı ile ilgili literatür genellikle bebek ve erken çocukluk dönemi ile ilgili çalışmalarda farklı sonuçlardan bahsetmektedir (Karama ve diğerleri 2011; Skeer ve diğerleri 2011). Yapılan bu çalışmanın bulgularında genel gelişimleri değerlendirilen 0-72 aylık çocuklarda anormal ya da şüpheli gelişim gösteren erkek çocukların kız çocuklardan oransal olarak daha fazla olduğu görülmüştür. Denver II GTT sonucuna göre anormal ya da şüpheli gelişim gösteren çocuklarda bütün alanlarda desteğe ihtiyaç duyan erkek çocuk sayısı kız çocuk sayısından daha fazladır. Gelişimsel değerlendirme istemiyle erkek çocukların sayıca kızlardan daha fazla yönlendirilmesi, bu durumu ortaya çıkaran nedenler arasında gösterilebilir. Ancak bu oranlar araştırmanın bütününde tüm gelişim alanları için aynı sonucu vermektedir. Yani dil gelişim alanında yaşanan sorunlar, dil ve motor alan gerilikleri ya da sosyal alanda yaşanan sorunlarda erkek çocukların kızlardan daha fazla desteğe ihtiyacı olduğu görülmüştür. Bazı gelişimsel alanlarda ise oranlar birbirine daha yakın olarak bulunmuştur. Örneğin motor alanda ya da motor alanın ve sosyal alanın birlikte güçlük yaşandığı durumlarda cinsiyetler arası belirgin farklılıklardan bahsetmek mümkün değildir. Bu çalışmada sadece ince motor alanda kız çocukların erkek çocuklardan daha fazla desteğe ihtiyacı olduğu sonucuna ulaşılmıştır. Literatürde cinsiyet ve gelişim özellikleri arasındaki ilişkiler incelendiğinde özellikle davranışsal alandan yapılan bazı çalışmalar kız ve erkek çocuklar arasında davranışsal problemlerin içselleştirilmesi veya dışsallaştırılması konusunda anlamlı farklılıklar bulmuşlardır. (Cederblad ve diğerleri 1996). Bunun yanı sıra erkek çocukların zihinsel olarak yaşadıkları problemlerin kız çocuklardan daha yüksek olduğunu bildiren çalışmalar da mevcuttur (Knoester ve diğerleri, 2007).

Yapılan bu çalışmada 0-72 aylık çocukların yaşları toplam 6 gruba ayrılarak incelenmiştir. Erken müdahale ünitesinde değerlendirilen çalışma grubu içerisinde anormal ve 
şüpheli gelişim gösteren çocukların yoğunlukla 13-24 aylık yaş grubundan olduğu görülmüştür. Benzer şekilde Bailey ve arkadaşlarının ABD'nin Kuzey Carolina eyaletinde yaptığı bir çalışmada, erken müdahale için sevk edilen çocukların ortalama 13-15 ay civarında olduğu belirtilmiştir (Bailey et al.2004). Ancak yapılan başka bir araştırmada çocuk sağlığ 1 ve gelişimi kliniğinde değerlendirilen ve tedavi edilen çocukların yaş ortalamasının 3-4 yaş aralığında olduğu ifade edilmiştir (Juneja et al.2005). Bu durum bazı araştırmacıların varsayımına göre, birçok gelişimsel sorunun çocuk doktorları tarafından daha çok 3 yaşına gelmiş çocuklarda belirlenmesi ve yönlendirmenin de bu yaş grubunda daha çok yapılması ile alakalı olabileceği üzerinedir (Kaur ve diğ., 2006; Strong \& Dingwall, 2018).

$\mathrm{Bu}$ çalışmada, gelişimsel olarak anormal ya da şüpheli olarak belirlenen çocuklardan Denver II GTT'ye göre tüm alanlarda desteğe ihtiyacı olan çocukların en yüksek oranı oluşturduğu görülmektedir. Bu yüksek oranları dil gelişimindeki gecikmeler ve kaba motor alanda yaşanan sorunlar izlemektedir. Benzer şekilde, literatürde Kaur ve ark tarafindan 2006'da yapılan çalışmada vakaların \%49'unun dil ve konuşma problemleri olduğunu bu vakaların \% 28 'inin sözel iletişime sahip olduğu, çocukların \% 22'sinde ise henüz konuşmanın başlamadığı bildirilmiş ve bunun için dil terapistine yönlendirildikleri belirtilmiştir (Kaur et al.2006). Case-Smith (2002) tarafından yapılan bir çalışmada ise motor alanda özellikle de ince motor becerilerdeki sorunların en sık karşılaşılan zorluklar olduğu belirtilmiştir (Case-Smith, 2002). Ayrıca yapılan birçok çalışmada bu çalışmanın bulgularına benzer nitelikte sonuçlara ulaşılmış, çocuklarda dil ve motor alanın gelişimsel yetersizliği olan çocuklarda müdahale gerektiren önemli bir alan olduğu üzerinde durulmuştur (Lean ve diğ., 2018; Maes, 2018)

\section{Sonuç}

$\mathrm{Bu}$ çalışmada Hacettepe Üniversitesi İhsan Doğramacı Çocuk Hastanesindeki Değerlendirme ve Erken Müdahale Ünitesine başvuran temsili bir örneklemin gelişimsel değerlendirme sonuçlarına yer verilmiştir. Bulgular bize başvuran çocuklara yönelik gelişimsel değerlendirmenin ve desteğin ne kadar önemli olduğunu gözler önüne serse de ulusal düzeyde bir tahmin elde edebilmek için ülke bazında tüm gelişim ünitelerinin verileri birleştirilerek daha ayrıntılı sonuçlar elde edilebileceği düşünülmektedir. Yapılabilecek böyle geniş çaplı bir araştırma Türkiye'deki çocukların gelişimsel ihtiyaçları ve hizmet kullanımları ile ilgili bilgilerimizi büyük ölçüde genişletecektir. Böylelikle mevcut politikaların geliştirilebileceği de öngörülmektedir.

$\mathrm{Bu}$ çalışmanın sonuçları, erken tarama, erken müdahale ve gelişimsel riskler için aile ile toplum üzerindeki yükü azaltmak adına gelişimsel değerlendirme ve destek ihtiyacını açıkça vurgulamaktadır. Bunun yanı sıra, gelişimsel değerlendirmenin ve desteğin erken müdahaleye katılım ile birlikte tüm çocuklara sunulmasına yönelik var olan engellerin kaldırılmasının ne denli 
önemli olduğunu gözler önüne sermektedir. Elbette ülkemiz şartları değerlendirildiğinde çok sayıda desteğe ihtiyacı olan ancak şu anda hizmet görmeyen çocuklara bu hizmetlerin sağlanması kolay olmayacaktır. Ancak hastaneye herhangi bir nedenle başvuran 0-6 yaş aralığındaki her çocuğa en az bir kere gelişimsel değerlendirme yapılarak desteklenmesinin uzun vadede sağlığın iyileştirilmesi ailenin ve toplumun güçlendirilmesi için inanılmaz sonuçlar doğuracağı kesindir. $\mathrm{Bu}$ bağlamda çocuğun gelişimini en iyi bilen çocuk gelişimcilere olan ihtiyaç gün geçtikçe artmaktadır.

Hiç şüphesiz bu çalışmanın sonuçlarını ulusal olarak desteklemek için daha fazla araştırmaya gereksinim vardır. Bu bağlamda daha geniş bir coğrafi alanda geniş bir kesitsel çalışma yapılması önerilmektedir. Ayrıca, bu çalışmanın sınırlamalarından birisi geriye dönük doğası olarak gösterilebilir. Değerlendirmenin sadece klinik olarak yapılması ve gelişimsel gecikmenin çeşitli yönlerini saptamak için tasarlanmış başka bir ölçek kullanılmaması da sınırlılıklar arasındadır. Dolayısıyla, verilen desteğin çok daha uzun süreli bir takip gerektirecek ve bu süreci ele alacak boylamsal çalışmalara ve vaka çalışmalarına ihtiyaç vardır. Bununla birlikte, bu çalışmanın bulguları gelişimsel gecikmesi olan çocuklar için Erken Müdahale olanakları oluşturmak ve geliştirmek için önemli görülmektedir. Yapılan bu çalışma, özellikle riskli gelişim gösteren gruplar için, ülkenin diğer bölgelerinde bu tür hizmetlerin sunulmasında iyi uygulama örneği ve kılavuz olma niteliği de taşımaktadır.

\section{Kaynaklar}

Akman, B., \& Öğretmenliği, O. Ö. (2018). Keyhole Erken Müdahale Programının Ebeveyn Ve Çocuk Çıktıları Üzerindeki Etkisi.

American Psychiatric Association. (2013). Diagnostic and statistical manual of mental disorders (DSM-5®). American Psychiatric Pub.

Anlar, B., \& Yalaz, K. (1996). Denver II Gelişimsel Tarama Testi Türk Çocuklarına Uyarlanması ve Standardizasyonu. Hacettepe Çocuk Nörolojisi Gelişimsel Tıp Araştırmaları Grubu. Ankara. s. 19-21.

Bailey, D. B., Hebbeler, K., Scarborough, A., Spiker, D., \& Mallik, S. (2004). First experiences with early intervention: a national perspective. Pediatrics, 113(4), 887-896.

Blanchard, L. T., Gurka, M. J., \& Blackman, J. A. (2006). Emotional, Developmental, and Behavioral Health of American Children and Their Families: A Report From the 2003 National Survey of Children9s Health. Pediatrics, 117(6), e1202-e1212.

Bricker, D. D., Felimban, H. S., Lin, F. Y., Stegenga, S. M., \& Storie, S. O. M. (2020). A Proposed Framework for Enhancing Collaboration in Early Intervention/Early Childhood Special Education. Topics in Early Childhood Special Education, 0271121419890683.

Büyüköztürk, Ş. (2009). Kılıç Çakmak, E. E., Akgün, Ö, E., Karadeniz, Ş., ve Demirel, F. 
Case-Smith, J. (2002). Effectiveness of school-based occupational therapy intervention on handwriting. American Journal of Occupational Therapy, 56(1), 17-25.

Cederblad, M., Friberg, B., Ploman, F., Sjöberg, N. O., Stjernqvist, K., \& Zackrisson, E. (1996). Children: Inteffigence and behaviour in children born after in-vitro fertilization treatment. Human Reproduction, 11(9), 2052-2057.

Courchesne, E., \& Pramparo, T. (2018). U.S. Patent No. 10,002,230. Washington, DC: U.S. Patent and Trademark Office.

Côté, S. M., Orri, M., Tremblay, R. E., \& Doyle, O. (2018). A multicomponent early intervention program and trajectories of behavior, cognition, and health. Pediatrics, 141(5).

Dall'Alba, L., Gray, M., Williams, G., \& Lowe, S. (2014). Early Intervention in Children (0-6 Years) with a Rare Developmental Disability: The Occupational Therapy Role. Hong Kong Journal of Occupational Therapy, 24(2), 72-80.

Ensink, J. B., de Moor, M. H., Zafarmand, M. H., de Laat, S., Uitterlinden, A., Vrijkotte, T. G., ... \& Middeldorp, C. M. (2020). Maternal environmental risk factors and the development of internalizing and externalizing problems in childhood: The complex role of genetic factors. American Journal of Medical Genetics Part B: Neuropsychiatric Genetics, 183(1), 17-25.

Hannigan, L. J., Pingault, J. B., Krapohl, E., McAdams, T. A., Rijsdijk, F. V., \& Eley, T. C. (2018). Genetics of co-developing conduct and emotional problems during childhood and adolescence. Nature human behaviour, 2(7), 514-521.

Juneja, M., Mukherjee, S. B., \& Sharma, S. (2005). A descriptive hospital based study of children with autism. Indian pediatrics, 42(5), 453.

Kalra, V., Seth, R., \& Sapra, S. (2005). Autism — experiences in a tertiary care hospital. The Indian Journal of Pediatrics, 72(3), 227-230.

Karasar, N. (2010). Bilimsel Arastirma Yontemi, Nobel Yayin Dagitim, 21. Basim, Ankara.

Kaur, P., Chavan, B. S., Lata, S., Kaur, A., Tinku, S., Arora, Y., \& Ratnam, V. (2006). Early intervention in developmental delay. The Indian Journal of Pediatrics, 73(5), 405-408.

Knoester, M., Helmerhorst, F. M., van der WESTERLAKEN, L. A., Walther, F. J., \& Veen, S. (2007). Matched follow-up study of 5-8-year-old ICSI singletons: child behaviour, parenting stress and child (health-related) quality of life. Human Reproduction, 22(12), 3098-3107.

Lean, R. E., Paul, R. A., Smyser, T. A., Smyser, C. D., \& Rogers, C. E. (2018). Social adversity and cognitive, language, and motor development of very preterm children from 2 to 5 years of age. The Journal of pediatrics, 203, 177-184. 
Maes, L. (2018). Correlation between motor and language skills at extremely poor and reference children in Ethiopia (Master's thesis, UHasselt).

McCarton CM, Wallace IF, Bennett FC. (1996). Early intervention for low-birth-weight premature infants: What can we achieve? Ann Med 28:221-225, 9

Rosenberg, S. A., Zhang, D., \& Robinson, C. C. (2008). Prevalence of developmental delays and participation in early intervention services for young children. Pediatrics, 121(6), e1503e1509.

Sengupta, U., Kumar, A., Gupta, S., Anthony, F., \& Nizamie, A. (2008). Early intervention in developmental delay. The Indian Journal of Pediatrics, 75(4), 393-397.

Sheridan, M. A., McLaughlin, K. A., Winter, W., Fox, N., Zeanah, C., \& Nelson, C. A. (2018). Early deprivation disruption of associative learning is a developmental pathway to depression and social problems. Nature communications, 9(1), 1-8.

Skeer, M. R., McCormick, M. C., Normand, S. L. T., Mimiaga, M. J., Buka, S. L., \& Gilman, S. E. (2011). Gender differences in the association between family conflict and adolescent substance use disorders. Journal of Adolescent Health, 49(2), 187-192.

Strong, P. M., \& Dingwall, R. (2018). The ceremonial order of the clinic: Parents, doctors and medical bureaucracies. Routledge.

Swaminath, D., Hefner, J., Jenkins, L. A., Suarez, J. A., Meyerrose, G., \& Huerta, T. R. (2018). Improving Clinical Documentation in an Academic Setting: A Multidisciplinary Team Approach Focused on the Physician's Perspective. Journal of Healthcare Management, 63(5), e88-e98.

Tekola, B., Girma, F., Kinfe, M., Abdurahman, R., Tesfaye, M., Yenus, Z., ... \& Servili, C. (2020). Adapting and pre-testing the World Health Organization's Caregiver Skills Training programme for autism and other developmental disorders in a very low-resource setting: Findings from Ethiopia. Autism, 24(1), 51-63.

Zwaigenbaum, L., Bauman, M. L., Choueiri, R., Kasari, C., Carter, A., Granpeesheh, D., ... \& Pierce, K. (2015). Early intervention for children with autism spectrum disorder under 3 years of age: recommendations for practice and research. Pediatrics, 136(Supplement 1), S60-S81. 